\title{
Correction: improvement of design of a surgical interface using an eye tracking device
}

\author{
Duygun Erol Barkana ${ }^{*}$, Alper Açık ${ }^{2}$, Dilek Goksel Duru ${ }^{3}$ and Adil Deniz Duru ${ }^{4}$
}

\author{
* Correspondence: duygunerol@ \\ yeditepe.edu.tr \\ ${ }^{1}$ Electrical and Electronics \\ Engineering Department, Yeditepe \\ University, Istanbul 34755, Turkey
}

\section{Correction}

After publication of this work [1], we noted that we inadvertently failed to include the complete list of all co-authors. The full list of authors has now been added and the Authors' Contributions and Competing Interests sections modified accordingly.

\section{Competing interests}

The authors declare that they have no competing interests.

\section{Authors' contributions}

DEB conceived and designed the research. DEB, AA, DGD, ADD performed the research including data collection, testing and analysis. DEB suggested extensions and modifications to the research. DEB supervised the whole research, and revised the manuscript critically. All authors read and approved the final manuscript.

\section{Acknowledgements}

We gratefully acknowledge the help of Prof. Mehmed Ozkan, who is Institute of Biomedical Engineering of Bogazici University, and Dr. M. Oner Sanli, who is in the Urology Department of Istanbul Faculty of Medicine in Istanbul University, for their valuable feedback about the surgical interface. We gratefully acknowledge the help of Prof. Fethi Calisir, who is in the Industrial Engineering Department of Istanbul Technical University, for his valuable feedback during the design, implementation and analysis of the questionnaires to investigate the importance of usability and functionality factors. We acknowledge the help of Gokcer Eskikurt during data collection from the eye tracking system.

\section{Author details}

${ }^{1}$ Electrical and Electronics Engineering Department, Yeditepe University, Istanbul 34755, Turkey. ${ }^{2}$ Psychology Department, Özyeğin University, Istanbul 34794, Turkey. ${ }^{3}$ Biomedical Engineering Department, Istanbul Arel University, Istanbul, Turkey. ${ }^{4}$ School of Physical Education and Sports, Marmara University, Istanbul, Turkey

Received: 22 September 2014 Accepted: 22 September 2014

Published: 3 November 2014

\section{Reference}

1. Barkana DE, Açık A: Improvement of design of a surgical interface using an eye tracking device. Theor Biol Med Model 2014, 11(Suppl 1):S4.

\section{doi:10.1186/1742-4682-11-48}

Cite this article as: Barkana et al:: Correction: improvement of design of a surgical interface using an eye tracking device. Theoretical Biology and Medical Modelling 2014 11:48. 